УДК 303.732

DOI: $10.14451 / 1.198 .102$

\title{
ВЛИЯНИЕ ИНФОРМАЦИОННОЙ СРЕДЫ НА ЗОЖ-ОРИЕНТИРОВАННОСТЬ НАСЕЛЕНИЯ
}

\section{(c) 2021 Родионов Дмитрий Григорьевич}

доктор экономических наук, профессор, Высшая инженерно-экономическая школа Санкт-Петербургский политехнический университет Петра Великого, Россия, Санкт-Петербург E-mail: dmitry.rodionov@spbstu.ru

\section{(C) 2021 Абдульманова Алсу}

студент, Высшая инженерно-экономическая школа

Санкт-Петербургский политехнический университет Петра Великого, Россия, Санкт-Петербург E-mail:miss.abdulmanova@mail.ru

\section{(c) 2021 Конников Евгений Александрович}

кандидат экономических наук, доцент, Высшая инженерно-экономическая школа Санкт-Петербургский политехнический университет Петра Великого, Россия, Санкт-Петербург E-mail: konnikov.evgeniy@gmail.com

В последнее время появляются новые сферы влияния на общественное сознание и поведение, к ним относятся СМИ, различные интернет-площадки, социальные сети, информационное пространство. Это дает пропаганде ЗОЖ движущую силу для трансформации. В наше прогрессивное и быстро меняющееся время продвижение концепции ЗОЖ форсировано стало развиваться благодаря Интернету, социальным сетям и информационной среде в целом. Цель исследования - выявление значимости и формулировка рекомендаций в рамках воздействия информационного фона для повышения ЗОЖ-ориентированности населения. Для достижения поставленной цели были проанализированы данные информационной среды относительно востребованности вопросов по ведению здорового образа жизни. К их числу относятся данные из социальной сети VK (ВКонтакте) и количество запросов в поисковой системе Google. Практическая значимость данной работы заключается в том, что материалы и результаты исследования могут быть применены для дальнейших исследований в сферах приближенных к здравоохранению не только для понимания насущного состояния ЗОЖ-ориентированности населения, но и для разработки механизмов и перспектив развития в нынешних и прогнозируемых социально-демографических и социально-экономических условиях в государстве. Обратим внимание, что проблема весомая и обширная, поэтому на нее не может влиять только обособленно взятая информационная среда и ее влияние на ЗОЖ-ориентированность населения. Следовательно, концепция и соблюдение здорового образа жизни населения, по существу, исходит и зависит от социально-экономической ситуации в том или ином сообществе. Например, в государстве, поскольку, чем здоровее население той или иной страны, тем меньше она затрачивает расходы на здравоохранительную сферу, которая составляет немалую часть государственного бюджета.

Ключевые слова: ЗОЖ (здоровый образ жизни), фитнес и здоровье, концепция развитого ЗОЖ, информационная среда.

Под ЗОЖ-ориентированностью человека, группы людей, населения в данной работе будут подразумеваться представления человека, группы людей, населения о здоровье, здоровом образе жизни, реальная практика постоянного самопобуждения к реализации требований ЗОЖ, действия с различной степенью активности по сохранению и укреплению здоровья и формированию здорового образа жизни. Прежде всего,

релевантность настоящей работы продиктована фактом, заявляющим, что в современном мире в последнее время появляются новые сферы влияния на общественное сознание, а именно: СМИ, различные интернет-платформы, социальные сети, информационное пространство, открытые для любого мнения. Это в свою очередь дает основу трансформации идеи ЗОЖ в новое представление людей о ведении своего привычного 
и сформировавшегося образа жизни. Продвижение концепции здорового образа жизни форсировано стало развиваться благодаря информационной среде.

C актуальностью заявленной проблематики можно сопоставить тезис работы Дж. Лонг, Л. Эллис, и Дж. Брейтуэйт «Исследования социальных сетей в медицинских учреждениях: разработка и сбор данных», в котором авторы утверждают, что исследования социальных сетей могут помочь нам понять неразрешимые проблемы, которые являются ключевыми для вызовов современной системы здравоохранения [1]. Несомненно, положительным фактором в сложившихся реалиях стала доступность донесения информации до широкой аудитории.

Также, хотелось бы указать основные тезисы отечественных авторов работ о здоровье и информационных технологиях. В частности, Журавлева И.В. в статье «Информированность в сфере здоровья и источники ее формирования», относя в качестве индикатора эффективности формирования в отношении здоровья СМИ как один из каналов информирования населения [2]. Более того, в статье БургановойЛ.А. и Савельевой Ж.В. «Медикализация и эстетизация здоровья в рекламной коммуникации» выявлено, что в настоящее время основными источниками информирования являются СМИ [3]. При этом отличительной особенностью СМИ является то, что они руководствуются в своей деятельности исключительно коммерческими интересами: любая реклама и информация о здоровье, даже если она наносит вред человеку, может появиться в СМИ. С этим тезисом сходится во мнении Вараксин А.В., автор статьи «Влияние социальных сетей на формирование ценностных ориентиров современной молодежи», утверждая, что представители современной прогрессивной молодежи переносят сформированные в виртуальном мире нормы и ориентиры в область реальной жизни и живого общения, формируя жизненную позицию и свои привычки [4].

Однако есть в популяризации концепта ЗОЖ в социальных сетях и отрицательная сторона. Массовость некоторых ошибочных суждений может отражать некорректные ориентиры и вектора развития среди населения. Данный тезис не разделяется автором работы «Средства массовой информации как механизм формирования ценностного отношения населения к своему здоровью» Шапаловой О. А.Идея автора направлена на положительную тенденцию влияния информационной среды на формирование населением ориентиров концептов 3ОЖ [5].

В целом сложно судить о поляризации эффектов ЗОЖ-ориентированности и СМИ, поскольку глобализация информационного пространства и технические достижения превратили СМИ в мощнейший фактор воздействия на картину мира отдельного человека. Однако, в статье Максимушкиной Е.А. и Вериной Т.П. «Влияние современных масс-медиа (интернета и социальных сетей в частности) на изменение концепта «здоровый образ жизни» среди молодежи» тезисом выступает факт популярности концепта «ЗОЖ» благодаря интернету и социальным сетям [6]. Таким образом, обозначим, что уровень информированности, наличие установок и ориентаций на ЗОЖ, реальная практика постоянного самопобуждения к реализации требований 30Ж в настоящее время является насущными вопросами современности.

Анализ теоретико-методологического базиса позволяет сформулировать гипотезу относительно зависимости ЗОЖ-ориентированности человека от состояния и комплексных характеристик информационной среды. Центральную значимость в рамках исследования воздействия информационной среды на ЗОЖ-ориентированность населения представляет собой информация из социальных сетей media. В текущей работе будет анализироваться информация из записей и содержимого, посвященных фитнес и здоровью, групп отечественной социальной сети VK (ВКонтакте), а именно такая количественная информация, как количество просмотров, лайков и репостов записей. На рисунке 1 представлена концептуальная модель данного исследования. В рамках данной концептуальной модели выделены два глобальных уровня: первый - две моноэндогенные модели, второй - моноэкзогенная модель. В данных двух моделях множественной регрессии центроидом выступает зависимый показатель доли граждан, ведущих здоровый образ жизни в 2019 году в распределении по агрегированным регионам в федеральные округа. Однако, для соблюдения логики исследования в блоке концептуальной модели, где регрессоры - это независимые переменные по информации из социальной сети VK, преобразована зависимая переменная из доли граждан, ведущих 3ОЖ, в количество подписчиков в группах о фитнесе и ЗОЖ. Взаимозаменяемость дан- 
ных двух переменных оправдана дополнительным исследованием модели парной регрессии. В составной концептуальной модели второй уровень представлен в моноэкзогенном виде. Данное исследование предполагает нахождение множества эндогенных переменных, описывающих демографическую ситуацию, связанную со смертностью и заболеваемостью теми или иными болезнями, которые теоретически сопоставлены с низкой численностью людей, ведущих и соблюдающих идею здорового образа жизни.

Зависимость влияния информационной среды на долю граждан, ведущих ЗОЖ посредством вовлеченности отдельного количества людей, подписчиков фитнес-сообществ, в процессы просматривания, оценивания и распространения соответствующей информации в своих личных страницах социальной сети ВКонтакте анализируется через уравнение множественной регрессии в виде:

$$
Y=3415,79+0,014 * X_{1}+2,15 * X_{2}-39 * X_{3}
$$

Анализ процесса влияния информационной среды и его компонент позволяет сформировать универсальный автоматизированный алгоритм

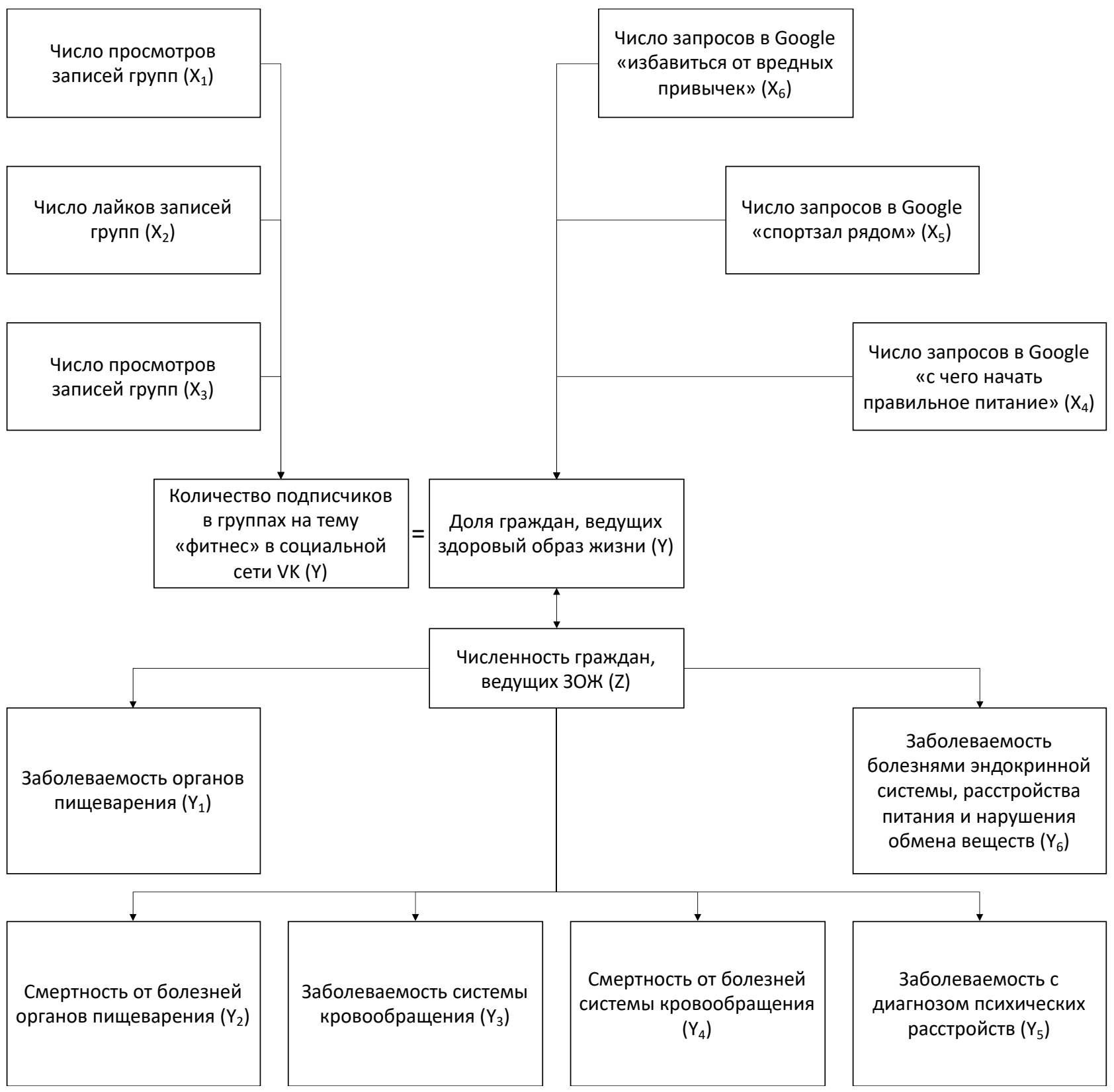

Рисунок 1. Концептуальная модель исследования 
калькуляции ЗОЖ-ориентированности населения. Началом алгоритма является формирование первичного массива данных, для которого производится агрегирование показателей информационной среды, а именно информация по количеству просмотров, лайков и репостов записей групп, посвященных теме фитнеса в социальной сети ВКонтакте в соответствии с анализируемым временным периодом - 2019 год. Как уже было отмечено ранее, оптимальным источником первичной информации в данном случае выступает отечественная социальная сеть ВКонтакте, что в первую очередь обусловлено эффективным сбором релевантной информации среды в группах, основной тематикой которых является фитнес, восьми соответствующих столицах федеральных округов.

Для целей автоматизированного парсинга социальных media данной информации может быть использован язык программирования Python 3, библиотекой Requests, текстовым форматом обмена данными json и модуль CSV, который предоставляет возможность выполнять структурный анализ файлов CSV. Важно отметить, что процедура парсинга VK неразрывно связана с API ВКонтакте, т.е. интерфейсом, который позволяет получать информацию из базы данных vk.com с помощью http-запросов к специальному серверу. Отметим, что данная социальная сеть имеет открытый API, изучение архитектуры которой позволяет производить парсинг данной media. При этом, синтаксис запросов и тип возвращаемых ими данных строго определены на стороне самого сервиса.

Уравнение множественной регрессии относительно информации по запросам из поисковой сети Google:

$$
Y=14,26-0,053 * X_{4}-0,006 * X_{5}+0,03 * X_{6}
$$

Таким образом, гипотеза о необходимости изучения влияния запросов из поисковой сети Google связанных с тематикой здорового образа жизни на долю граждан, ведущих здоровый образ жизни, не подтвердилась. Проанализированная модель множественной регрессии и уравнение по ней не достаточны для разработки предложений и системы управления информационной среды на ЗОЖ-ориентированность населения. Причина неудачной реализуемости данной модели может заключаться в разрыве статистических данных с точки зрения про- странственного распределения. Условно можно допустить, что заинтересованность запросов по данной тематике крайне индивидуальна для того или иного региона. Учтем при этом, что поисковые данные были взяты изолированно по одному условному ключевому региону в каждом федеральном округе за один год.

Далее обозначим второй уровень исследования, представленный множеством уравнений парной регрессии, где гипотеза на уровне распределения регионов Российской Федерации заключается в том, что социально-экономический показатель, связанный с долей населения ведущего ЗОЖ, неизменно влияет на значения демографических показателей смертности и заболеваемости теми или иными болезнями населения.

$$
\begin{aligned}
& \mathrm{Y}_{1}=3910,26-0,001 * \mathrm{Z} \\
& \mathrm{Y}_{2}=76,46-0,000021 * \mathrm{Z} \\
& \mathrm{Y}_{3}=2981,65-0,0005 * \mathrm{Z} \\
& \mathrm{Y}_{4}=582,6-0,0000288 * \mathrm{Z} \\
& \mathrm{Y}_{5}=2670,77-0,00033 * \mathrm{Z} \\
& \mathrm{Y}_{6}=1451,12-0,00014 * \mathrm{Z}
\end{aligned}
$$

Моноэкзогенная модель парной регрессии описала крайне малые проценты дисперсии. Отсюда возникает вопрос о значимости исследования, поэтому необходимо стремление к максимизации коэффициента детерминации. Таким образом, несмотря на исключение данной модели из исследования, она может использоваться в других исследования и быть их базой.

Полученные результаты исследования находят последовательное отражение в существующем теоретико-методологическом базисе. Сущность результата первой модели множественной регрессии резонирует с главным тезисом статьи Бредихиной Н.В. «Ориентация населения на здоровый образ жизни» о том, что уровень информированности, наличие установок и ориентаций на ЗОЖ, реальная практика постоянного самопобуждения к реализации требований ЗОЖ в настоящее время является насущными вопросами современности [7]. Это нашло свой отклик и в методологии и специфике сбора данных, в поиске которых руководство шло, в первую очередь, со стороны показателей информационной среды социальной сети ВКонтакте и поисковых запросов на темы здорового образа жизни, спорта, повышения иммунитета и избавления от вредных привычек.

Примечателен факт сопоставления резуль- 
татов исследования с основной мыслью статьи авторов Дж. Лонг, Л. Эллис, и Дж. Брейтуэйт «Исследования социальных сетей в медицинских учреждениях: разработка и сбор данных» [1]. Авторы полагают, что сейчас существуют неразрешимые проблемы, которые связаны с информационной средой и являются ключевыми для вызовов современной системы здравоохранения. В ходе настоящего исследования было установлено, что предположение о влиянии развития активной концепции ЗОЖ и его медиирование на глобальные показатели социального и демографического характера по стране на 2019 год было опровергнуто ввиду незначительных результатов по данной модели.

Автор работы «Средства массовой информации как механизм формирования ценностного отношения населения к своему здоровью» Шапалова О.А. выражает в ней идею положительной тенденции влияния информационной среды на формирование населением ориентиров концепции ЗОЖ [5]. В общем и целом, данный тезис автора и результаты по концептуальным моделям сопоставимы и представляют собой вектор направлений воздействия волнующих показателей на улучшение ситуации с 30Ж-ориентированностью населения. Потенциальный эффект от воздействия управления информационной среды в рамках данной тематики, может проявляться в предполагаемом повышении заинтересованности и вовлеченности населения страны в активную позицию ЗОЖ. Не исключено, что одновременно это сможет оптимизировать другую концептуальную зависимость между показателями здравоохранительной сферы, а именно заболеваемость и смертность от тех или иных болезней, которые зачастую возникают путем игнорирования ведения здорового образа жизни. Для этого могут потребоваться годы.

Однако, учтем, что популярность наблюдается в настоящее время концепта ЗОЖ благодаря интернету и социальным сетям, как утверждается в статье Максимушкиной Е.А. и Вериной Т.П. «Влияние современных масс-медиа (интернета и социальных сетей в частности) [6]. Это означает, что результаты исследования, согласно статье Рощиной Я. «Микроэкономический анализ отдачи от инвестиций в здоровье» объясняют необходимость изучения и обобщения информации по лучшим практикам 30ж, размещения в открытом доступе, например в популярных социальных сетях, корректной информации по здоровому образу жизни [8].

Завершая обсуждение результатов исследования, обратимся к автору статьи «Мероприятия по повышению эффективности муниципальной молодежной политики», Евстратовой Т.А., выражающей мысль о глобализации информационного пространства и технических достижений [9]. Именно они трансформируют информационную среду в мощнейший фактор воздействия на отдельного человека. Воздействие информационного поля на установки и образ жизни человека не ограничивается формированием мнения о том или ином объекте. Под влиянием набора установок может сложиться образ мышления, определяющее общее мировоззрение.

Таким образом, на основании вышеописанных предложений по управлению зависимыми переменными, в рамках исследования концептуальная модель частично сошлась и при этом не наблюдается значимой метадинамики. В ходе исследования и анализа уравнений регрессии было выяснено, что единственной достоверной и значимой оказалась первая модель множественной регрессии. Вторая модель множественной регрессии, в которой агрегировалась пространственная информация из Google Trends, была бы нецелесообразна в рамках данного исследования. Вполне вероятно, что при появлении новых официальных статистических данных за период времени более года по доле граждан, ведущих 30Ж, данная модель может быть пересмотрена и оптимизирована с учетом временного лага, что предоставит важные и значимые результаты для понимания проблемы влияния информационной среды на ЗОЖ-ориентированность населения и своевременной разработки комплексных мер в стране по данной проблеме.

В свою очередь, модель парной регрессии также не подтвердилась, что является значительным результатом. Можно предположить, что причины несостоятельности этой модели неразрывно связаны с временным лагом в десятки лет, при том, что статистические данные в Российской Федерации по главному результирующему признаку имеются только за 2019 год. Помимо этого, такой результат может быть связан с необходимостью системной поддержки населением здорового образа жизни.

Наиболее вероятно, что зависимость продвижения концепции ЗОЖ от информационной среды будет развиваться и меняться далее с течением времени, после чего можно будет 
прогнозировать изменения, в направлении которых должен поменяться окружающий мир, чтобы силы связей зависимых и независимых переменных можно было исследовать более эффективно. Кроме того, можно предположить, что причины несостоятельности модели парной регрессии, где зависимыми от численности населения, ведущего ЗОЖ, переменными являлись демографические и социальные показатели страны только за 2019 год, связаны с необходимостью расчета временного шага в десятки лет. Также, это может быть связано с потребностью системной поддержки населением страны здо- рового образа жизни.

Направления дальнейших исследований могут быть ориентированы на более детальные анализы воздействия информационной среды на здоровье и ЗОЖ-ориентированность населения страны, а также на разработку комплекса действий со стороны государства для выгодного снижения рассмотренных демографических показателей в здравоохранительной сфере страны. Также, исследования могут быть направлены на разработку способов медиирования развития концепции активной идеи здорового образа жизни.

\section{Библиографический список}

1. Chiara Pomare, Janet C. Long, Kate Churruca, Louise A. Ellis, Jeffrey Braithwaite. Social network research in health care settings: Design and data collection // Social Networks, 2019, ISSN 0378-8733, DOI: https://doi.org/10.1016/j. socnet.2019.11.004.

2. Журавлева И.В. Информированность в сфере здоровья и источники ее формирования / И.В.Журавлева // Сборник трудов конференции «Охрана здоровья: проблемы организации, управления и уровни ответственности», 2007.

3. Бурганова Л.А., Савельева Ж.В. Медикализация и эстетизация здоровья в рекламной коммуникации // Социологические исследования. 2009. № 8 (304). С. 100-107.

4. Вараксин А. В. Влияние социальных сетей на формирование ценностных ориентиров современной молодежи // Преподаватель ХХІ век. 2016. № 2-1. С. 205-212.

5. Шаповалова О.А. Средства массовой информации как механизм формирования ценностного отношения населения к своему здоровью: теоретико-методологические основы анализа // Социология медицины. 2008. № 2 (13). С. 15-19.

6. Максимушкина Е.А., Верина Т.П. Влияние современных масс-медиа (интернета и социальных сетей в частности) на изменение концепта «здоровый образ жизни» среди молодежи // Наука, образование и культура. 2016. № 11 (14). С. 59-60.

7. Бредихина Н.В. Ориентации населения на здоровый образ жизни: региональный аспект // диссертация на соискание ученой степени кандидата социологических наук / Челябинск, 2006.

8. Рощина Я. М. Микроэкономический анализ отдачи от инвестиций в здоровье в современной России // Экономический журнал Высшей школы экономики. 2009. Т. 13. № 3. С. 428-451.

9. Евстратова Т.А. Мероприятия по повышению эффективности муниципальной молодежной политики малого город // Материалы Ивановских чтений. 2015. № 5 (5). С. 20-25.

10. Юлдашева О.У., Погребова О.А. Формирование модели поведения потребителей на рынке товаров и услуг здорового образа жизни // Труды БГТУ. № 7. Экономика и управление. 2015. № 7 (180). С. 28-33.

11. Конникова О.А. Формирование стандартов потребления на рынке здорового образа жизни на принципах преактивного маркетинга // диссертация на соискание ученой степени кандидата экономических наук / Санкт-Петербургский государственный экономический университет. Санкт-Петербург, 2015

12. Погребова О.А. Концептуальные основы формирования стандартов потребления на рынке здорового образа жизни // Маркетинг менеджмент в цифровой экономике. 2016. Т. 2. № 1. С. 51-69.

13. Конников Е.А., Терентьева Д.А., Конникова О.А. Анализ уровня устойчивого потребления в контексте цифровой информационной среды // Экономические науки. 2020. № 192. С. 114-125.

14. Ершова А.В., Родионов Д. Г., Конников Е.А., Конникова О.А. Системный анализ привлекательности банков для представителей ВИП-сегмента потребителей в рамках цифровой информационной среды // Экономические науки. 2021. № 194.

15. Родионов Д.Г., Конников Е. А., Мугутдинов Р. М. Системный анализ конкурентоспособности цифрового предприятия в рамках информационной среды // Экономические науки. 2020. № 193. С. 394-401.

16. Родионов Д.Г., Конников Е.А., Алферьев Д.А. Информационный капитал предприятия как целевой показатель развития в рамках цифровых экономических систем // Экономические науки. 2020. № 190. С. $131-137$. 